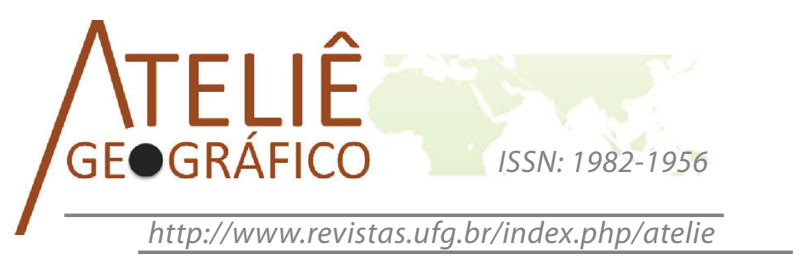

\title{
Os efeitos dos programas de desenvolvimento rural LEADER e PRODER em territórios rurais deprimidos de Portugal: o caso das Terras de Sicó
}

\section{The effects of the rural development programs, called LEADER and PRODER, in deprived rural areas of Portugal: the case of the Terras de Sicó}

\section{Los efectos de los programas de desarrollo rural LEADER y PRODER en territorios rurales deprimidos de Portugal: el caso de las Tierras de Sicó}

Flávio de Arruda Saron

Universidade Estadual Paulista - Campus de Presidente Prudente

flaviosaron@yahoo.com.br

Antonio Nivaldo Hespanhol

Universidade Estadual Paulista - Campus de Presidente Prudente nivaldo@fct.unesp.br

\begin{abstract}
Resumo
No artigo são analisados os efeitos da implementação da Iniciativa Comunitária Ligações Entre Ações do Desenvolvimento da Economia Rural (LEADER) e do Programa de Desenvolvimento Rural (PRODER) no desenvolvimento dos territórios rurais deprimidos de Portugal, especialmente das Terras de Sicó, área coberta pelos dois programas de desenvolvimento rural cofinanciados pela União Europeia. Constatou-se que os referidos programas, voltados prioritariamente para áreas rurais deprimidas não têm sido suficientes para reverter o caráter deprimido da maioria dos territórios rurais portugueses, incluindo as Terras de Sicó. As áreas deprimidas continuam a perder população e a ampliar as áreas destinadas a sistemas agrícolas extensivos (principalmente silvicultura). Tal fato decorre do arranjo das políticas no âmbito do bloco europeu, da conjuntura macroeconômica e das limitações da IC LEADER e do PRODER para alavancarem o desenvolvimento dos territórios rurais deprimidos. Palavras-chave: Desenvolvimento rural, Agricultura, Territórios deprimidos, Portugal, Terras de Sicó.
\end{abstract}




\begin{abstract}
This article examines the effects of the implementation of the Community Initiative Links Among Rural Economic Development Actions (LEADER) and the Rural Development Program (PRODER,) in the development of the deprived rural areas of Portugal are analyzed, especially the Terras de Sicó, an area covered by these two rural development programs co-financed by the European Union. It was found that these programs, with priorities set for deprived rural areas, have not been sufficient to reverse underdeveloped nature of most Portuguese rural areas, including the Terras de Sico. These deprived areas continue to lose population and to have expanding areas for extensive farming systems (especially forestry). This is due to a set of the policies within the European block, and to macroeconomic situation and the limitations of the IC LEADER and PRODER to promote the development of the deprived rural territories. Keywords: Rural Development, Agriculture, Deprived Territories, Portugal, Terras de Sicó.
\end{abstract}

\begin{abstract}
Resumen
En el artículo se analizan los efectos derivados de la implementación de la Iniciativa Comunitaria «Ligações Entre Ações do Desenvolvimento da Economia Rural» (LEADER) (en español Vinculaciones Entre Acciones del Desarrollo de la Economía Rural) y del «Programa de Desenvolvimento Rural» (PRODER) (en español Programa de Desarrollo Rural) sobre el desarrollo de los territorios rurales deprimidos de Portugal, especialmente de las Tierras de Sicó, área cubierta por los dos programas de desarrollo rural cofinanciados por la Unión Europea. Se constató que los referidos programas, destinados prioritariamente a áreas rurales deprimidas, no han sido suficientes $\mathrm{p}$ ara r evertir e $1 \mathrm{c}$ arácter deprimido de $\mathrm{la}$ m ayoría de los territorios rurales portugueses, incluyendo las Tierras de Sicó. Las áreas deprimidas continúan perdiendo población y ampliando las áreas destinadas a sistemas agrícolas extensivos (principalmente silvicultura). Tal hecho se debe a la disposición de las políticas en el ámbito del bloque europeo, de la coyuntura macroeconómica y de las limitaciones de IC LEADER y del PRODER para apalancar el desarrollo de los territorios rurales deprimidos.
\end{abstract}

Palabras clave: Desarrollo rural, Agricultura, Territorios deprimidos, Portugal, Tierras de Sicó.

\title{
Introdução
}

O presente texto é fruto das reflexões desenvolvidas em nosso estágio de pesquisa no exterior, realizado na Universidade de Coimbra (UC), Portugal $^{1}$.

Serão realizadas reflexões e analisadas as problemáticas relacionadas a eficiência dos programas de desenvolvimento rural direcionados aos territórios rurais deprimidos,

1. O estágio foi realizado entre 04 de maio e 02 de setembro de 2013 (período de quatro meses), e contou com apoio financeiro da Fundação de Amparo à Pesquisa do Estado de São Paulo (FAPESP) na modalidade Bolsa de Estágio Bolsa de Estágio de Pesquisa no Exterior (BEPE) (Processo número 2013/04639-6). O estágio de pesquisa vinculou-se ao projeto de pesquisa (nível Mestrado regular no país) intitulado: "Políticas Públicas, Agricultura Familiar e Desenvolvimento Territorial no Noroeste Paulista", com a orientação do Professor Doutor Antonio Nivaldo Hespanhol e supervisão no exterior do Professor Catedrático Lúcio José Sobral da Cunha e Professor Rui Manuel Missa Jacinto, ambos da UC. 
especificamente a Iniciativa Comunitária (IC) Ligações Entre Ações do Desenvolvimento da Economia Rural (LEADER) e o Programa de Desenvolvimento Rural (PRODER), especificamente o subprograma 3) Dinamização das Zonas Rurais, que deu continuidade a abordagem LEADER, a partir do ano de 2007.

Trata-se de intervenções corretivas das distorções regionais no espaço rural provocadas pela dinâmica capitalista, e comumente reforçada por políticas setoriais e produtivistas, a exemplo da Política Agrícola Comum (PAC). A IC LEADER é considerada um marco por ser a primeira intervenção de grande envergadura a aplicar os pressupostos inovadores da abordagem territorial nas políticas públicas voltadas ao espaço rural. A instituição do referido programa se insere em contextos mais amplos que consideram além das ações voltadas exclusivamente a agricultura para promover o desenvolvimento rural, passando a ser valorizada a multifuncionalidade do espaço rural e a participação direta dos atores sociais.

No estágio de pesquisa realizamos levantamento bibliográfico e documental acerca de temas como: os desdobramentos da integração de Portugal ao bloco europeu no que tange a agricultura e ao desenvolvimento econômico; os efeitos dos programas comunitários para a agricultura e o desenvolvimento rural em Portugal. Foi realizada investigação empírica no território das Terras de Sicó (com realização de entrevista com o representante da Associação de Desenvolvimento Local do referido território), atividades que sustentaram nossas discussões e reflexões no âmbito da pesquisa.

O texto esta organizado em duas partes, além dessa breve introdução e das considerações finais.

Na primeira parte discutimos as implicações advindas da integração de Portugal a então Comunidade Econômica Europeia (CEE), em 1986, atualmente União Europeia (UE), articuladas as mudanças ocorridas no âmbito das políticas voltadas ao espaço rural no bloco europeu, especialmente o advento da IC LEADER no ano de 1991.

Em seguida analisamos os efeitos da implementação IC LEADER e do PRODER nas Terras de Sicó, um dos muitos territórios rurais deprimidos portugueses cobertos pelos referidos programas.

\section{Desdobramentos da integração de Portugal a Comunidade Econômica Europeia (CEE) e seus efeitos para a agricultura e o desenvolvimento rural}

A adesão de Portugal a CEE no ano de 1986 é um divisor de águas para o país, assinalou um ciclo de transformações produtivas, sociais e culturais sem precedentes. Boa parte dessas mudanças foi induzida pelo acesso que o país passou a ter aos fundos e programas comunitários, os quais proporcionaram significativa melhoria da qualidade de vida da população, e principalmente na infraestrutura física do país, sobretudo as voltadas para aos transportes (autoestradas, obras viárias urbanas etc.).

Entretanto, para alguns setores, como a agricultura, o balanço entre os ganhos e perdas decorrentes da integração comunitária é negativo. As razões para isso são apresentadas por Silva (2000), e dizem respeito basicamente a não consideração das particularidades, atrasos e desníveis da agricultura portuguesa em comparação a outros países europeus, especialmente situados no Centro e no Norte da Europa. 
Relativamente aos países do sul nomeadamente Portugal, a PAC, além de desadequada à pequena agricultura do norte e centro do país, despreocupouse dos efeitos económicos e sociais sobre tais agriculturas: abandono de produção, despovoamento, apoio à agricultura intensiva com custos ambientais e em prejuízo das agriculturas de subsistência e biológica, canalização de subsídios para as áreas económica e tecnologicamente mais evoluídas (SILVA, 2000, p. 72).

Antes da integração a CEE, Portugal já dependia da importação de alimentos, tendo saldo negativo na balança comercial agrícola. Após a incorporação do país ao bloco europeu a pressão sobre a frágil e pouco competitiva agricultura ampliou-se, e aprofundou algumas tendências que já estavam em curso no que diz respeito a agricultura e ao espaço rural, como: a redução do emprego agrícola e do peso da agricultura na composição da renda das famílias rurais, seja oriunda de atividades externas a agricultura ou por pensões; o crescimento das áreas não cultivadas e de áreas com culturas e atividades extensivas (em especial de florestas e eucaliptos), dentre outras, conforme aponta Cavaco (2006).

Com a adesão de Portugal ao bloco europeu, o país passou a ter acesso aos fundos e ICs da UE, que são definidas a cada ciclo quinquenal no âmbito do Quadros Comunitários de Apoio (QCA), QCA I, QCA II, QCA III, Quadro de Referência Estratégica Nacional (QREN) e, atualmente em vigor (2014-2020) Quadro Estratégico Comum (QEC), descritos no quadro 1.

A integração regional proporcionou grande ampliação e diversificação no repertório de medidas, ações e programas voltados à agricultura e ao espaço rural em Portugal. Além da PAC, o país passou a contar com programas operacionais nacionais de apoio à agricultura e ao desenvolvimento rural cofinanciados por fundos comunitários (Fundo Agrícola de Desenvolvimento Rural - FEADER; Fundo Europeu de Desenvolvimento Regional FEDER e Fundo Social Europeu - FSE) e outras iniciativas comunitárias que incidem sobre a agricultura Programas Integrados Mediterrâneos (PIM), Programa Específico de desenvolvimento da Agricultura Portuguesa (PEDAP), Programa de Apoio à Modernização da Agricultura Portuguesa (PAMAP), Programa Operacional de Agricultura e Desenvolvimento Rural (POADR), INTERREG agricultura e desenvolvimento regional, e o desenvolvimento rural (LEADER, PRODER) conforme demonstra o quadro 1.

Quadro 1. Linha evolutiva dos programas e ICs de apoio a agricultura e ao desenvolvimento rural segundo os QCAs, o QREN em Portugal.

\begin{tabular}{|l|l|l|l|l|}
\hline $\mathbf{1 9 8 6 - 1 9 8 8}$ & $\mathbf{1 9 8 9 - 1 9 9 3}$ & $\mathbf{1 9 9 4 - 1 9 9 9}$ & $\mathbf{( 2 0 0 0 - 2 0 0 6 )}$ & $\mathbf{2 0 0 7 - 2 0 1 3}$ \\
\hline QCA & QCA I & QCA II & QCA III & QREN \\
\hline PAC & PAC & PAC & PAC & PAC \\
\hline PIM & PEDAP & PAMAP & POADR & \\
\hline & LEADER I & LEADER II & LEADER + & PRODER \\
\hline & INTERREG & INTERREG & INTERREG & \\
\hline
\end{tabular}

Fonte: $<$ http://www.qca.pt/acessivel/pos/agro.asp $>;<$ http://ec.europa.eu/agriculture/rurdev/index_pt.htm> Org. Flávio de Arruda Saron. 
No quadro 1 são apresentados, de forma bastante sucinta, os programas e ações de apoio a agricultura e ao desenvolvimento rural na UE no período 1986-2013 definidas a cada ciclo, nos quais novos eixos e prioridades foram definidos a partir das negociações realizadas no âmbito do Conselho Europeu.

Os programas listados no quadro 1 visaram conduzir o país a transição de forma menos traumática a novos contextos econômicos, sociais e culturais propiciados pela incorporação ao bloco europeu. Entretanto, estas ações e programas compensatórios não minimizaram os efeitos negativos para a agricultura e os territórios rurais portugueses, conforme apontam Jacinto e Alves (2013).

Algumas das explicações para este desfecho são atribuídas às mudanças nas diretrizes em relação às políticas voltadas ao espaço rural ocorridas no âmbito do bloco europeu, iniciadas nos anos 1980 e aprofundadas nos anos 1990 e 2000.

As principais mudanças referem-se à reforma nos fundos estruturais e na PAC (1992, 1999 e 2003), e a implementação da “Agenda 2000”, que resultaram na adoção de medidas de liberalização da agricultura e ampliação dos incentivos ao desenvolvimento rural, que passou a se constituir no segundo pilar da PAC ${ }^{2}$. A estratégia para a agricultura e o mundo rural foi estruturada em torno de três objetivos, quais sejam: "modernizar o modelo agrícola europeu; reduzir as assimetrias regionais em termos de riqueza e de perspectivas económicas; controlar as despesas (aumentos orçamentais moderados até 2006)" (CARVALHO, 2008, p. 73). Em termos práticos:

Trata-se de complementar as reformas dos mercados - centradas na redução dos preços garantidos nos sectores das culturas arvenses, carne de bovino, leite e produtos lácteos e vitinícolas - com outras acções que promovam uma atividade agrícola mais competitiva e multifuncional (CARVALHO, 2008, p.74).

Concluiu-se que a agricultura é uma atividade importante, mas incapaz por si só de garantir o desenvolvimento rural. Dessa forma, novas perspectivas de desenvolvimento para os espaços rurais passaram a ser consideradas com o intuito de reduzir o peso da agricultura como "única" estratégia de desenvolvimento rural, privilegiando a integração de atividades (agricultura, turismo rural, trilhas etc.), explorando comercialmente as tradições rurais, o patrimônio, a paisagem, os recursos naturais etc. A tônica é o esforço de integração de políticas e diversificação da base econômica, dando corpo, assim, a abordagem territorial do desenvolvimento.

Ao nível orçamentário, a figura 1, mostra a evolução dos gastos no âmbito da PAC entre as suas principais modalidades, dentre elas o desenvolvimento rural no período compreendido entre os anos de 1980 e 2010.

Verifica-se na figura 1 a ampliação dos gastos com o desenvolvimento rural, ao mesmo tempo em que o incentivo a expansão da agrícola (em especial as Restituições à exportações) diminuíram consideravelmente. Embora tenham sido destinados mais

2. O desenvolvimento rural é entendido pelas instituições governamentais europeias como a aplicação de ações e projetos compactuados com os agricultores e a sociedade civil, "preocupados" com a diversificação de atividades no meio rural, como o turismo rural (para compensar a perda de importância da agricultura), a manutenção da paisagem e a qualidade dos recursos naturais dentre outros aspectos. 
recursos ao desenvolvimento rural, ao nível orçamentário, no entanto, esta vertente das políticas voltadas aos espaços rurais continua sendo minoritária.

Nesse contexto de "projeção" do desenvolvimento rural foi criada a IC LEADER. A despeito do otimismo exagerado depositados nas novas metodologias e filosofias nos programas de desenvolvimento rural, Cunha (2004) demonstra que as restrições ao primeiro pilar da PAC não foram benéficas para a agricultura portuguesa e a maioria dos seus territórios rurais, uma vez que o atraso estrutural e econômico da agricultura requeria justamente ações vinculadas ao primeiro pilar da $\mathrm{PAC}^{3}$.

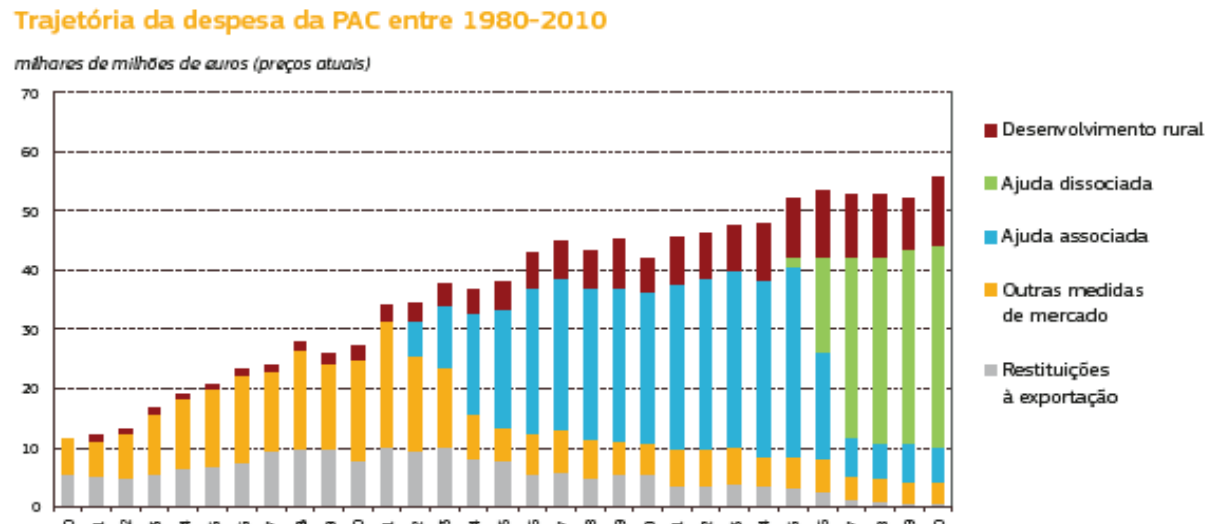

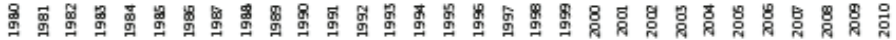

Figura 1. Trajetória da despesa da PAC entre 1980-2010.

Fonte: COMISSÃO EUROPÉIA. A politica agrícola comum - A história continua. Luxemburgo: Serviço das Publicações da União Europeia, 2012, p. 09.

A IC LEADER passou a ser executada no ano de 1991, e contou com financiamento do Fundo Europeu de Orientação e Garantia Agrícola - FEOGA (em 2005 o FEOGA converteu-se no FEADER, dando mais destaque ao desenvolvimento rural) e dos governos nacionais (são exigidas contrapartidas financeiras dos beneficiários dos projetos). A boa receptividade que a IC obteve, levou a UE a editar outras duas edições do programa, de modo a expandir e incentivar os países a adotarem a abordagem LEADER em programas nacionais de desenvolvimento rural. Assim, o programa é dividido em três fases, LEADER I (1991-1993), LEADER II (1994-1999) e LEADER+ (2000 - 2006).

Cada nova fase do programa contou com a ampliação do orçamento, por extensão dos recursos alocados e do número de projetos financiados e áreas contempladas. $\mathrm{O}$ LEADER I contou com orçamento de 442 milhões de euros (€), distribuídos em 217 territórios, o LEADER II com recursos da ordem de 1,755 bilhões $€$ e apoiou 893

3. Cunha (2004) narra à resistência da UE e as dificuldades do Ministério da Agricultura e do Mar português em inserir essas questões na Comissão Europeia, citando motivos de ordem estritamente políticos, que explicitam as assimetrias no poder de decisões no bloco europeu. 
territórios, enquanto que para o LEADER+ foram disponibilizados 2,105 bilhão de $€$, apoiando 906 territórios (COMUNIDADES EUROPEIAS, 2006).

A expansão do LEADER, consequentemente implicou no aumento do número de projetos apoiados pelo programa em Portugal e em sua cobertura territorial, uma vez que boa parte do território português é constituído de áreas consideradas prioritárias do LEADER, ou seja, territórios rurais deprimidos, que se caracterizam pelo êxodo de jovens, envelhecimento da população, atraso tecnológico e baixa produtividade da agricultura, dentre outros aspectos.

A marginalização econômica destas áreas possibilitou que se mantivesse conservada em grande medida as paisagens rurais, as quais passaram a ser valorizadas para a exploração do turismo no espaço rural. Num contexto geral da assunção de uma visão idílica do rural construída a partir de novos valores de uma sociedade predominantemente urbana, mais preocupada com o meio ambiente, com a permanência das tradições e particularidades do modo de vida rural, que foram muito abalados pela padronização do consumo e do modo vida induzidos pela globalização (BAPTISTA, 2006).

Nesse sentido, o programa LEADER despertou grandes expectativas quanto ao potencial de desenvolvimento contido nessas áreas, conforme se verifica em Cavaco (1992) e Barros (2003). Entretanto, estudos mais recentes, a exemplo de Moreno (2004 e 2009), Carneiro (2005) e Rover e Henriques (2006), apontam que o programa teve impactos bastante limitados, e os territórios rurais contemplados com a IC LEADER e outros programas de desenvolvimento local continuam a perder população e a apresentar baixo dinamismo econômico (JACINTO; ALVES, 2013).

Moreno (2004) destaca que houve resistências e tensões em relação à adoção da metodologia LEADER ${ }^{4}$.

No caso português, a implantação do LEADER e da sua dinâmica ocasionou uma série de conflitos internos, por inerência à colisão entre um planejamento e controlo administrativo tradicional, de tendência centralizadora e institucionalista, e aquele que supõe a participação activa das entidades locais. A penetração deste último modelo foi quase uma "revolução silenciosa". Se é verdade que o PIC LEADER foi bem recebido pelo governo português, pela promessa da mitigação da crise da agricultura e do meio rural que se fazia sentir de forma intensa, não é menos verdade que a condução interna do processo escapou à sua lógica de planeamento e gestão territorial, vindo a desagradar a vários responsáveis técnicos e políticos afectos ao Ministério do Planeamento e à Direcção-Geral do Desenvolvimento Regional (DGDReg), bem como a responsáveis de várias autarquias locais que sentiam "intrusões em seus domínios". De facto, já não era novo o conflito de perspectivas entre aqueles que apostavam na "qualificação territorial" por via funcionalista (planeamento centrado na perspectiva económica dominante) e os que defendiam abordagens multicentradas, envolvendo a participação da população no ordenamento. A

4. A dificuldade em operar na lógica ascendente e descentralizada preconizadas pela IC LEADER também foi verificada em outros países europeus, conforme aponta Werner (1999). 
experiência e/ou a sensibilidade de muitos técnicos e responsáveis do Ministério da Agricultura, a que pertencia o Organismo Nacional Intermediário para o PIC [Programa Iniciativa Comunitária] LEADER, faziam apontar para esta última via (MORENO, 2004, p. 109).

Na tabela 1 e na figura 2 são apresentados alguns dados referentes às três edições do programa LEADER em Portugal. Os projetos do LEADER I incidiram em 1950 freguesias em Portugal, cobrindo uma área de 37\% do continente, nas quais residiam $14,3 \%$ da população. O LEADER II apresenta significativa expansão em relação ao seu antecessor, atingindo 54\% da área territorial do continente, distribuídas em 2914 freguesias em que residiam $32,6 \%$ da população. Ao passo que no LEADER+ todos os territórios rurais se tornaram elegíveis ${ }^{5}$, entretanto, $89 \%$ deles foram atingidos, onde residiam 35\% da população de Portugal Continental.

Tabela 1. Performance do Programa LEADER em Portugal Continental (não contempla a Ilha da Madeira e os Açores).

\begin{tabular}{|l|c|c|c|}
\hline & LEADER I & LEADER II & LEADER+ \\
\hline Área territorial abrangida & $37 \%$ & $86 \%$ & $89 \%$ \\
\hline População & $14,3 \%$ & $32,6 \%$ & $35 \%$ \\
\hline $\begin{array}{l}\text { Grupos de Ação Local (GALs) } \\
\text { constituídos }\end{array}$ & 20 & 48 & 52 \\
\hline
\end{tabular}

Fonte: Moreno (2004); Rover; Henriques (2006).

Org. Flávio de Arruda Saron.

Para apoiar as regiões rurais deprimidas, o programa foi estruturado em algumas linhas de atuação, de modo a contemplar as vocações, diversidades e características dessas regiões, conforme o quadro 2 demonstra como a IC LEADER esteve organizada nas suas três edições.

No entanto, Rover e Henriques (2006) ponderam que os territórios rurais identificados como rural profundo, entendidos como áreas rurais menos dinâmicas, onde a atividade agrícola é mais importante para a composição da renda das famílias rurais, e a possibilidade de ocupações não-agrícolas é bastante limitada, ou seja, as áreas que mais sofreram com o envelhecimento e redução da população. Os territórios rurais mais carentes de intervenção pública não foram alcançados pela IC LEADER em Portugal, pois são os que possuem o menor nível de organização política e têm mais dificuldades para garantir as contrapartidas exigidas no financiamento dos projetos.

Nesse sentido, Rover e Henriques (2006) observam que as Associações de Desenvolvimento Local (ADLs) são controladas, em grande medida, por tecnocratas vinculados as autarquias locais, especialmente câmaras municipais e juntas de freguesia, reproduzindo, dessa forma, uma situação de assimetria de poder característico de abordagens descendentes.

5. Entretanto, somente aqueles deprimidos estão habilitados a receber recursos do FEDER para ações do LEADER. 


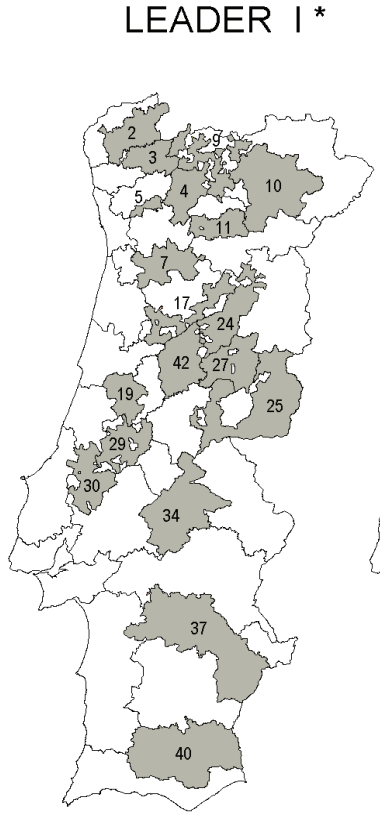

* Adaptado de MORENO (2002)
LEADER II *

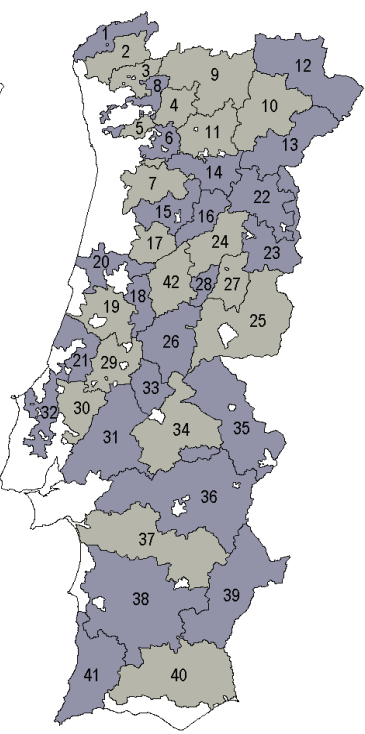

LEADER + **

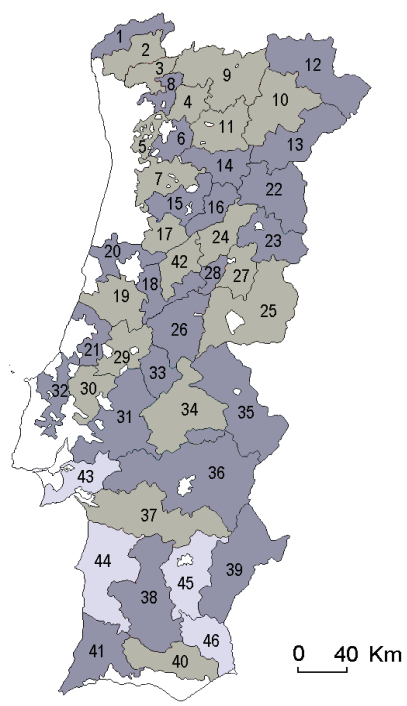

Figura 2. A Iniciativa Comunitária LEADER em Portugal Continental - Entidades Locais LEADER I (1991-93); LEADER II (1994-99); LEADER + (2001-06).

Fonte: http://www.sper.pt/VCHER/Pdfs/LuisMoreno.pdf

Quadro 2. LEADER em Portugal: principais Acções/Medidas.

\begin{tabular}{|l|l|l|}
\hline LEADER I & LEADER II & LEADER + \\
\hline $\begin{array}{l}\text { - Apoio Técnico ao Desenvolvimento } \\
\text { Rural }\end{array}$ & - (idem) & $\begin{array}{l}\text { - Apoio a estratégias de desenvolvimento } \\
\text { territorial integradas de carácter } \\
\text { inovador, baseadas numa abordagem da } \\
\text { base para o topo }\end{array}$ \\
\hline $\begin{array}{l}\text { - Formação Profissional e ajudas a } \\
\text { contratação }\end{array}$ & $\begin{array}{l}\text { - poucas mudanças em relação a } \\
\text { primeira versão }\end{array}$ & $\begin{array}{l}\text { - Apoio à cooperação entre territórios } \\
\text { rurais }\end{array}$ \\
\hline $\begin{array}{l}\text { - Turismo em espaço rural (TER) } \\
\text { - Pequena e Média Empresa (PME), } \\
\text { artesanato e serviços de apoio }\end{array}$ & $\begin{array}{l}\text { - (idem) } \\
\text { e Outros }\end{array}$ & - Criação de redes \\
\hline $\begin{array}{l}\text { - Valorização e comercialização de } \\
\text { produtos locais }\end{array}$ & $\begin{array}{l}\text { - poucas mudanças em relação a } \\
\text { primeira versão }\end{array}$ & - Assistência técnica \\
\hline - Outras medidas & $\begin{array}{l}\text { - Preservação e valorização do } \\
\text { ambiente e da qualidade de vida }\end{array}$ & \\
\hline - Funcionamento do GAL & $\begin{array}{l}\text { - Acções em cooperação (nacional/ } \\
\text { transnacional) }\end{array}$ & \\
\hline & - Outros & \\
\hline
\end{tabular}

Fonte: Adaptado de Moreno (2004) e <http://ec.europa.eu/agriculture/rur/leaderplus/intro_pt.htm $\geq$ (Acesso em 20/06/2013).

Org. Flávio de Arruda Saron. 
Os referidos autores fazem a seguinte observação sobre as limitações da IC LEADER no apoio aos territórios rurais mais fragilizados:

Desde o LEADER I até hoje, a necessidade de uma contrapartida financeira para cada projecto a aprovar é uma limitação que os agricultores mais descapitalizados não conseguem superar, até porque faltam em muitos locais mecanismos de micro-crédito que complementem a necessária parcela de recursos próprios. Por outro lado, também é limitado o envolvimento destes grupos nas tomadas de decisões estratégicas do desenvolvimento local, quer quanto às orientações gerais, quer no que se relaciona com a selecção dos projectos a aprovar. É evidente a necessidade de um esforço institucional de discriminação positiva destes grupos. Uma tal discriminação exige a superação do preconceito relativamente às capacidades dos grupos mais necessitados e desorganizados, e um maior investimento na sua formação/capacitação (ROVER; HENRIQUES, 2006, p. 130).

A IC LEADER chama mais atenção por seus aspectos diferenciados, do que propriamente por seus resultados efetivos. Almejava-se que a partir de projetos inovadores e exemplares de desenvolvimento rural as próprias comunidades rurais sejam responsáveis pelo desenvolvimento e sensibilizem outros territórios rurais a trilharem o mesmo caminho (MORENO, 2004; WERNER, 1999).

A despeito do seu caráter inovador e descentralizado, a restrição orçamentária é um dos principais entraves para a obtenção de resultados mais significativos em termos de promoção do desenvolvimento rural, constituindo este em ponto débil do programa, conforme nos apresenta Carneiro (2005). Segundo a autora, o LEADER+ dispunha de

[...] mais do dobro das suas dotações iniciais em 1991, tem uma dimensão bastante reduzida no total do orçamento comunitário, representando apenas cerca de 1\% das dotações dos Fundos Estruturais europeus, e 19,4\% das dotações para as Iniciativas Comunitárias para o período 2000-2006. Mais ainda, comparando com o orçamento concedido ao "segundo pilar" da PAC, o Desenvolvimento Rural (30.370 milhões de euros), o orçamento para o Programa LEADER, o único exclusivamente dedicado ao desenvolvimento rural, representa apenas cerca de 1/15 (CARNEIRO, 2005, p. 14).

As ações e programas compensatórios, que caracterizam as intervenções do desenvolvimento rural não minimizaram os efeitos negativos para a agricultura e os territórios rurais portugueses, conforme apontam Jacinto e Alves (2013).

As dinâmicas económicas, sociais e culturais das últimas décadas mudaram a face dos espaços rurais e expuseram debilidades que sucessivos ciclos de políticas de desenvolvimento foram incapazes de reverter, trajetórias que acentuaram com a adesão de Portugal à União Europeia e fortemente potenciadas com as subsequentes reformas da [...] PAC. As novas orientações das políticas comunitárias para o desenvolvimento rural inspiraram sucessivas gerações de políticas públicas, desde Iniciativas Comunitárias, onde releva, para este efeito, o LEADER, aos Quadros Comunitários de Apoio e respectivos 
Programas Operacionais (do PEDAP ao PRODER), cujos apoios financeiros, assimetricamente repartidos em termos geográficos e quanto ao tipo e dimensão das explorações beneficiárias, não geraram atividades alternativas nos espaços rurais nem minoraram a crescente perda de importância da agricultura (JACINTO; ALVES, 2013, p. 132).

Portanto, o cenário pouco promissor para a agricultura e os territórios rurais deprimidos em Portugal está relacionado, em grande medida, a aplicação de programas de desenvolvimento rural, e sua insuficiência em conter tendências e processos de longa data, especialmente o despovoamento das áreas rurais.

Tais problemáticas mantém atual o debate sobre a natureza, o formato e as ações dos programas de desenvolvimento rural voltados ao desenvolvimento dos territórios rurais deprimidos em Portugal.

A IC LEADER se encerrou no ano de 2006, entretanto, sua abordagem foi incorporada em programas nacionais de desenvolvimento rural a partir da vigência do QREN. No caso de Portugal, passou a integrar o Programa de Desenvolvimento Rural (PRODER), trata-se de programa português de desenvolvimento rural, que conta com recursos do FEADER e do país.

O PRODER foi oficialmente criado no ano de 2007, em consonância com as orientações estabelecidas pelo FEADER para a criação de programas nacionais de desenvolvimento rural. O programa aglutina as medidas e ações que estavam dicotomizadas nos QCA I, II e III nos Programas Operacionais da Agricultura e Desenvolvimento Rural e na IC LEADER. Ou seja, contempla o apoio à agricultura e também da vertente do desenvolvimento rural num único programa são apoiados a agricultura e o desenvolvimento rural.

O programa é dividido em quatro subprogramas, quais sejam: 1) Promoção da Competitividade; 2) Gestão Sustentável do Espaço Rural; 3) Dinamização das Zonas Rurais e 4) Promoção do Conhecimento e Desenvolvimento de Competências.

O programa é financiado com recursos do governo português, e em sua maior parte do FEADER, previa-se despesa pública total de 4.282.019 de euros, dos quais 3.573.777 $€$ provenientes do FEADER. Especificamente ao subprograma 3 (eixo LEADER) é direcionada uma parcela pouco expressiva dos recursos (comparando-se aos dois principais subprogramas do PRODER, quais sejam: 1) Promoção da Competitividade e 2) Gestão Sustentável do Espaço Rural), as verbas públicas destinadas são da ordem de 393.078€, cabendo ao FEADER a concessão de 315.948€ desse montante. Ou seja, apenas $9,18 \%$ do PRODER.

O subprograma 3, por sua vez é organizado e hierarquizado em medidas e ações descritas no quadro 3. O eixo LEADER do PRODER não apresenta diferenças nos princípios e diretrizes adotados na IC LEADER. As poucas mudanças verificadas se circunscrevem as formas de organização e operacionalização mais centralizadas do subprograma 3 do PRODER, em comparação a IC LEADER. 
Quadro 3. Medidas e ações do subprograma 3 (eixo LEADER) do PRODER.

\begin{tabular}{|c|}
\hline Medida 3.1 Diversificação da Economia e Criação de Emprego \\
\hline Ações: \\
\hline $\begin{array}{l}\text { 3.1.1 Diversificação de Atividades na Exploração Agrícola } \\
\text { 3.1.2 Criação e Desenvolvimento de Microempresas (CDM) } \\
\text { 3.1.3 Desenvolvimento de Atividades Turísticas e de Lazer (DATL) }\end{array}$ \\
\hline Medida 3.2 Melhoria da Qualidade de Vida \\
\hline Ações: \\
\hline $\begin{array}{l}\text { 3.2.1 Conservação e Valorização do Património Rural (CVPR) } \\
\text { 3.2.2 Serviços Básicos para a População Rural (SBPR) }\end{array}$ \\
\hline Medida 3.3 Implementação de Estratégias Locais de Desenvolvimento (ELD) \\
\hline Medida 3.4 Cooperação LEADER para o Desenvolvimento \\
\hline Ações: \\
\hline $\begin{array}{l}\text { 3.4.1Cooperação Interterritorial } \\
\text { 3.4.2 Cooperação Transnacional }\end{array}$ \\
\hline Medida 3.5 Funcionamento dos GAL, Aquisição de Competências e Animação \\
\hline
\end{tabular}

Os efeitos do PRODER, de uma forma geral têm sido os mesmos do LEADER. Tanto no que diz respeito a sua insuficiência em reverter a estagnação econômica e despovoamento das áreas rurais deprimidas, quanto em relação às Associações de Desenvolvimento Local (ADLs), incumbidas da gestão do PRODER a nível local, continuam a depender de "orientações e opções das políticas públicas e do seu financiamento que, não sendo coerentes e sempre no mesmo sentido, conduzem a constantes variações dos níveis de intervenção das ADL” (LOPES, 2012, p. 111).

A seguir, abordamos mais algumas problemáticas relacionadas às ADLs, bem como os efeitos da IC LEADER e do PRODER no território das Terras de Sicó.

\section{Resultados e implicações da implementação da IC LEADER e do PRODER e as ações para o desenvolvimento rural no território das Terras de Sicó}

O território Terras de Sicó, situado na região centro litoral de Portugal, congrega seis Concelhos ${ }^{6}$, quais sejam: Alvaiázere, Ansião, Condeixa-a-Nova, Penela, Pombal e Soure, conforme está representado no mapa 1 .

As Terras de Sicó abrangem uma área de $1.500 \mathrm{~km}^{2}$, e de acordo com o Recenseamento da população de 2011 somava um contingente de 117.938 habitantes, sendo Pombal o mais populoso com 55.217 de habitantes, seguido por Soure com 19.245, Ansião com 13.128, Alvaiázere com 7.287, Condeixa-a-Nova com 7.078 e Penela com 5.983 de habitantes.

6. Em Portugal, Concelho é sinônimo de Município. Os municípios citados integram a região centro de Portugal, os Concelhos de Alvaiázere, Ansião e Pombal integram o distrito de Leiria, enquanto que os Concelhos de Condeixa-a-Nova, Soure e Penela estão inseridos no distrito de Coimbra. 
Apesar de se localizar próximo a área mais dinâmica de Portugal, largamente servida por modernas vias de transporte e situar-se nas proximidades de cidades médias importantes, como Coimbra e Leiria, as Terras de Sicó apresentam tendências de desenvolvimento parecidas aos territórios rurais mais isolados do interior do país, identificados como rural profundo ${ }^{7}$, ou seja, constitui-se em um território rural deprimido, caracterizado pela estagnação econômica, processo de emigração e envelhecimento da população, sobretudo rural (CUNHA, 2003).

Para Cunha (2003), esse quadro econômico e social se deve em boa parte,

[...] as condições naturais decorrentes do processo de carsificação, têm feito com que o Maciço de Sicó assuma, ainda hoje, formas significativas de marginalidade territorial, com fraco dinamismo demográfico, económico, social e cultural.

Com efeito, o Maciço de Sicó, com muito fracas densidades populacionais [...], não tem parado de perder população [...]. Segundo valores do censo de 2001, praticamente todas as freguesias que constituem o núcleo do Maciço de Sicó apresentam densidades populacionais inferiores a $50 \mathrm{hab} / \mathrm{Km}^{2}$, valor que vem, inclusivamente abaixo dos $20 \mathrm{hab} / \mathrm{Km}^{2}$ nas freguesias do Furadouro. Apenas as freguesias marginais ao Maciço, ou seja, as que incluem no seu território as áreas baixas, mais ricas em água e mais férteis, atingem valores acima dos 50 $\mathrm{hab} / \mathrm{km}^{2}$ e apenas as freguesias de Condeixa, Condeixa-a-Velha e Pombal, de carácter mais marcadamente urbano, ultrapassam os $125 \mathrm{hab} / \mathrm{Km}^{2}$.

Estas baixas densidades populacionais são o resultado de um processo demográfico longo que envolveu a redução progressiva de taxas de natalidade, mas sobretudo a emigração, primeiro para o Brasil e, depois, com maior intensidade, para a Europa e a saída para os grandes centros urbanos, como Lisboa e, mais recentemente, para os pequenos centros urbanos da região (Pombal, Soure, Condeixa, Ansião). Seja como for, desde a década de sessenta que este processo não tem parado de verificar-se e, apesar das já muito baixas densidades, mesmo no último período intercensitário (1991 a 2001) a população diminuiu mais de $20 \%$ na freguesia de Pombalinho, entre 10 e $20 \%$ na maioria das freguesias serranas e apenas registou aumentos nas freguesias marginais e particularmente nas de carácter mais urbano (Pombal: 23\%; Condeixa: 45\%) (CUNHA, 2003, p. 189-191).

Afigura 3 apresenta o perfil da agricultura nas Terras de Sicó, qual seja: agricultura pouco dinâmica com vastas áreas ocupadas por sistemas agrícolas extensivos. Ao passo que os sistemas agrícolas mais intensivos, como a produção de gêneros alimentares, a vinha, dentre outros, que esporadicamente utiliza-se de regadios (irrigação) é praticada nos fundos de vales.

Sobre as características da agricultura nas Terras de Sicó ressalta-se o perfil envelhecido dos agricultores, a pequena participação da agricultura na composição da

7. Sobre os processos, dinâmicas e tendências evolutivas das referidas áreas, a coletânea organizada por Jacinto; Mendes e Batista (2009) fornecem várias perspectivas de estudos dessas áreas e várias problemáticas enfocadas. 
renda, ou seja, o caráter secundário que esta atividade representa, implica no exercício da agricultura de part time (tempo parcial) (MATEUS, 2009).

A proximidade das cidades de Coimbra e Leiria e a significativa melhoria na integração territorial ocorrida em Portugal após a adesão a CEE, fizeram com que as Terras de Sicó sofressem processo de rurbanização, com a fixação de moradores de média e alta renda, que desenvolvem suas atividades na cidade e se deslocam pendularmente para cidades maiores, havendo, também, a presença de segundas residências. Esse processo se reflete na instauração de novas dinâmicas econômicas, demográficas, alterações na paisagem, dentre outros processos, provocando mistura de construções de alto padrão e arquitetura urbana em meio a campos e residências tradicionais rurais (MATEUS, 2009).

Sobre a implementação da IC LEADER e do PRODER no referido território, é preciso analisar a trajetória e o papel exercido pela ADL-Terras de Sicó, órgão executor dos referidos programa.

A ADL-Terras do Sicó foi fundada no ano de 1995, e é fruto da ampliação e consolidação de uma outra associação, a Associação de Municípios da Serra de Sicó (ADSICÓ) constituída no ano de 1988 e que abrangia os municípios de Alvaiázere, Ansião, Condeixa-a-Nova, Penela, Pombal e Soure. Os municípios citados, juntamente com a Caixa de Crédito Agrícola de Pombal são os responsáveis pela manutenção e injeção de recursos a ADL-Terras de Sicó.

Sobre a evolução da ADL-Terras do Sicó, Cunha (2003) destaca que antes da sua fundação em 1995, ainda em 1992 a entidade já vinha atuando com vistas a implementar projetos apoiados por programas comunitários, em especial o LEADER.

Para Cunha (2003) a ADL-Terras de Sicó.

[...] tem vindo a promover um vasto programa de revitalização do espaço rural de Sicó, através de iniciativas ligadas, sobretudo, à valorização dos produtos tradicionais, à promoção da actividade turística e à melhoria das infraestruturas da região serrana. A par com estas, outras iniciativas institucionais e individuais, públicas e privadas têm vindo, a pouco e pouco, a modificar este espaço, valorizando-o, divulgando-o, criando localmente algum emprego, ou seja, contribuindo, de algum modo, para o desenvolvimento local de uma área economicamente deprimida e ambientalmente frágil.

Muito do trabalho da ADSICÓ, mais tarde transformada em Associação de desenvolvimento das Terras de Sicó, consistiu no aproveitamento de programas comunitários e, particularmente, do programa LEADER, para promoção de desenvolvimento rural. Ao longo das várias fases deste programa registaramse iniciativas de "apoio ao desenvolvimento Rural" (com particular destaque para as unidades de produção de vinho, mel, azeite e queijo), de "formação específica e ajudas à contratação", de "apoio à diversificação das atividades económicas", de "valorização e comercialização de produtos agrícolas" e de "preservação e valorização do ambiente". Particular atenção foi prestada, pelo menos no início e no âmbito do chamado Leader I, à promoção do mundo rural através do desenvolvimento de atividades de lazer e de turismo (recuperação do património; apoio à criação de infra-estruturas; divulgação), que apesar do carácter eventualmente discutível do sucesso de tais iniciativas, deixaram 
marcas bem vincadas na paisagem de Sicó e contribuíram, decisivamente, para a construção de uma imagem territorial que hoje assume relevante significado (CUNHA, 2003, p. 196-197).

Mapa 1. Localização do Território das Terras de Sicó - Portugal.

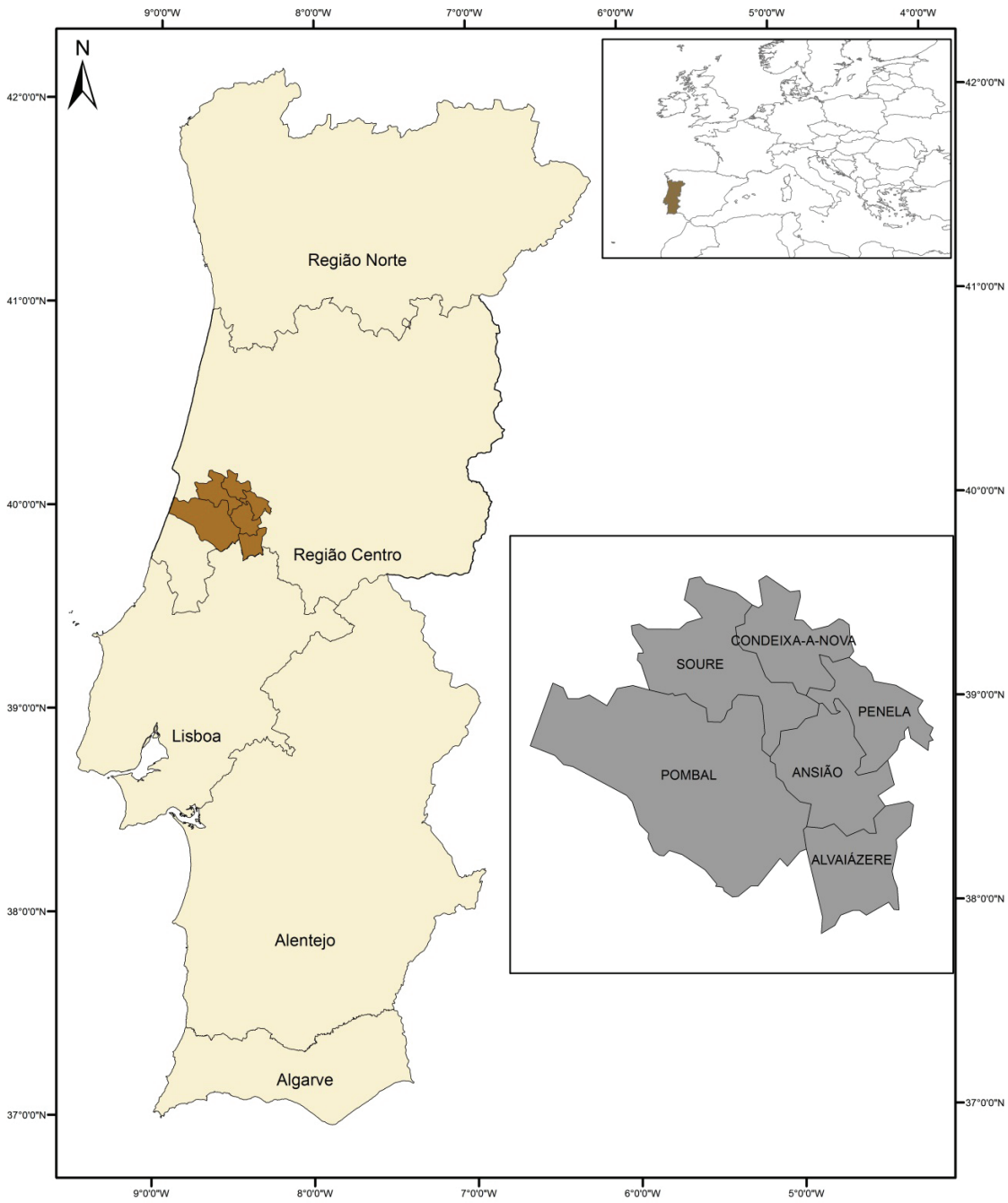

\section{Legenda:}

Terras de Sicó 


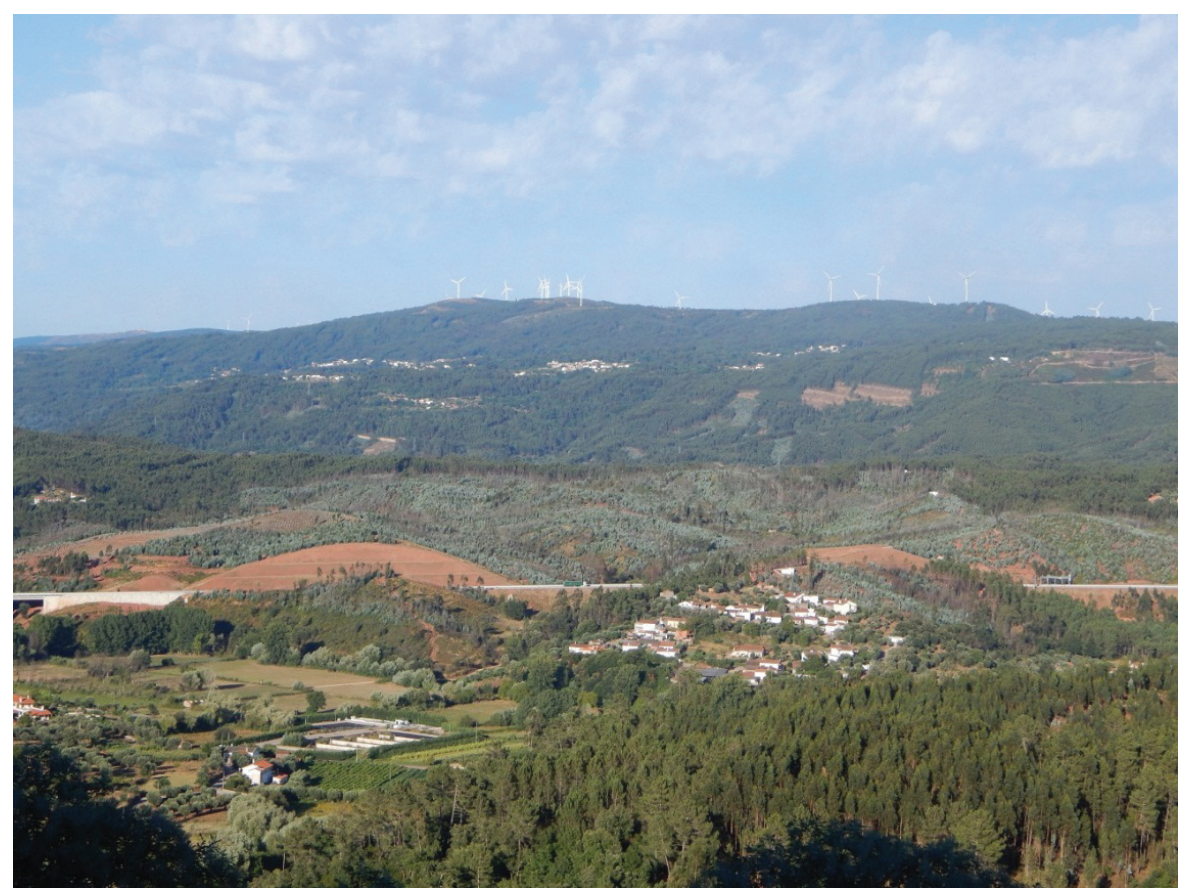

Figura 3. Espaço rural, Terras de Sicó.

Fonte: Pesquisa de Campo, 08/08/2013.Org. Flávio de Arruda Saron

Com a diluição do programa LEADER no PRODER, a ADL-Terras de Sicó passou a operar o subprograma 3 do PRODER $^{8}$. Entretanto, a atuação da ADL não está/ esteve voltada apenas para o acesso aos programas de desenvolvimento rural (LEADER e PRODER).

A organização também orienta-se para a implementação de projetos incentivados por outros programas de desenvolvimento financiados pelos fundos comunitários, como o Mais Centro e o Programa Operacional Regional do Centro e seu subprograma Programa de Valorização Económica dos Recursos Endógenos (PROVERE) que contam com financiamento do Fundo Social Europeu (FSE), mas busca financiamento de outros programas e fundos estruturais comunitários como o Fundo Europeu de Desenvolvimento Regional (FEDER) e FEADER ${ }^{9}$.

8. Os outros subprogramas do PRODER que financiam projetos voltados à modernização e reestruturação produtiva são operacionalizados separadamente, pela Direção-Geral do Desenvolvimento Regional (DGDR) vinculada ao Ministério da Agricultura e do Mar. A unidade da DGDR mais próxima das Terras de Sicó se localiza na cidade de Coimbra. Esta cisão indica a dicotomia existente entre os programas de apoio a agricultura e ao desenvolvimento rural.

9. Informações concedidas pelo representa da ADL-Terras do Sicó. Para mais informações dos projetos implementados pela ADL e os respectivos programas, ver: $<$ http://www.terrasdesico.pt/associacao-plano.php $>$. 
Na verdade, a ADL-Terras de Sicó tem sua atuação pautada na divulgação dos programas de desenvolvimento, buscando orientar e estimular a proposição de projetos, oferecendo assistência técnica e jurídica para os agentes do território elaborarem e pleitearem recursos dos programas de desenvolvimento e fundos estruturais comunitários. Para tanto, a ADL conta com uma sede física que se localiza no Concelho de Pombal, e dispõe de uma Equipe Técnica Local (ETL) ${ }^{10}$ que orienta e auxilia na elaboração das propostas, as quais serão, posteriormente, encaminhadas para a equipe gestora do PRODER, vinculada ao Ministério da Agricultura e do Mar.

Para a execução do PRODER, outro dispositivo necessário (obrigatório) é o GAL, trata-se de uma entidade de caráter consultivo que congrega os diversos agentes do território, cuja incumbência é definir o conteúdo da Estratégia Local de Desenvolvimento (ELD), ou seja, as prioridades, os objetivos o eixo norteador para as ações voltadas ao desenvolvimento dos territórios. O GAL é uma entidade parceira da ADL na gestão do PRODER $^{11}$, sendo que o seu presidente também preside a ADL, cabendo a essa entidade implementar a ELD.

Os projetos submetidos à ADL para o acesso a financiamentos parciais do PRODER podem ser apresentados individualmente, não havendo assim a necessidade de constituição formal de organizações de agricultores para o acesso a programas de desenvolvimento rural. Entretanto, para maior eficiência e potencialização dos projetos de desenvolvimento rural, a ADSICÓ, por meio de sua ETL, incentivou a organização dos agricultores em torno de associações e cooperativas, de modo a promover a cooperação de agricultores do mesmo segmento produtivo, tais como: queijo, vinho, azeite, mel, frutas, artesanato, dentre outros, de modo a facilitar a difusão de técnicas e procedimentos necessários à certificação dos produtos.

Ressalta-se que essas organizações foram instituídas de forma induzida, muito mais por conta da animação dos técnicos da ETL, do que pelo acesso direto a recursos e incentivos dos programas de desenvolvimento rural.

AADL-Terras de Sicó abre chamadas públicas para a apresentação de propostas que são apreciadas pela ETL com base em alguns critérios gerais, quais sejam: Valia Técnico Económica, Valia Estratégica, Análise Económica - Financeira; Postos de Trabalho ${ }^{12}$, entretanto, os critérios técnicos variam de acordo com a natureza de cada medida e ação.

Por meio do critério "Valia Estratégia" estipula-se que os projetos no âmbito do LEADER/PRODER devem valorizar os atributos das Terras de Sicó, ou seja, devem contribuir para tornar o "SICÓ, um território, uma marca" a partir dos diferentes projetos e ações envolvidas (3.1.2 CDM; 3.1.3 DATL; 3.2.1 CVPR; 3.2.2 SBPR e 3.4.2

10. O corpo técnico da ADL-Terras de Sicó é constituído por cinco profissionais, cada um com funções especificas e complementares, quais sejam: Administrativa; Administrativa e Financeira/Animação; Acompanhamento e Controlo/Cooperação; Análise de Projectos e um Coordenador da ETL/Cooperação.

11. O GAL é uma exigência para a implementação do PRODER. Segundo o representante da ADL entrevistado, na prática muitas ADLs portuguesas assumem funções do GAL, embora formalmente ele esteja constituído.

12. O PRODER financia $40 \%$ a fundo perdido se o projeto gerar ao menos um emprego e $60 \%$ para 2 empregos gerados. 
Cooperação Transnacional) cada qual contribuindo de uma forma particular para a consecução deste objetivo prioritário, pois cada ação contempla temáticas diferenciadas conforme o seu próprio nome sugere que variam desde o incentivo a atividades produtivas com potencial para a dinamização da economia local, a dotação de equipamentos de lazer coletivo.

A ADL-Terras de Sicó procura desenvolver projetos que valorizem as características do território, na agricultura, por exemplo, incentiva ações com a produção de produtos típicos e "únicos" do território, como o queijo rabaçal, priorizando agregar valor aos produtos. A ADL também busca valorizar outras "particularidades" do território como a exploração turística dos vestígios romanos, centro de interpretação da flora, dentre outros projetos que exploram os aspectos culturais e naturais das Terras de Sicó.

No que se refere aos projetos apoiados pela ADL-Terras de Sicó, o seu representante declarou que a associação não deve limitar seus esforços em torno de apenas um eixo de atuação (por exemplo, o turismo rural ou a agricultura), argumentando o pouco impacto que tal orientação geraria para o desenvolvimento do território.

Dentre as principais ações apoiadas pela ADL-Terras do Sicó com o financiamento da IC LEADER no período compreendido entre os anos de 1991 a 2006 (ver figura 4, projeto que teve apoio da IC LEADER), destacam-se a:

1) Denominação de Origem Protegida (DOP) - Queijo Rabaçal, ou seja, a obtenção da certificação de origem geográfica do produto (figura 4).

2) DOP e criação da zona demarcada de produção do mel Serra da Lousã.

3) Criação da sub-região de vinhos "Terras de Sicó”.

4) Estudo e demarcação de área para a produção do mel Serra de Sicó.

5) Estudo e demarcação de produção do cabrito e borrego de Sicó.

6) Estudo e identificação da flora e da fauna nas Terras de Sicó.

7) Constituição de organizações de produtores por produto qualificado.

8) Organização de certames de comercialização de produtos artesanais.

9) Estudo para a criação do Azeite Terras de Sicó.

Em relação a atuação do PRODER (subprograma 3) no território das Terras de Sicó, verifica-se que foram implementados projetos apoiados pelas seguintes medidas e ações:

a) Medida 3.1 Diversificação da Economia e Criação de Emprego. Ação 3.1.2 - CDM; Ação 3.1.3 - DATL.

b) Medida 3.2 Melhoria da Qualidade de Vida. Ação 3.2.1 - CVPR e 3.2.2 SBPR.

c) Medida 3.4 Cooperação LEADER para o Desenvolvimento. Ação 3.4.2 Cooperação Transnacional. 
O fato de nas Terras de Sicó serem implementados projetos apenas nessas medidas se deve as características do território e do percurso já consolidado anteriormente no LEADER $^{13}$. Moreno (2009) apresenta o perfil dos projetos do LEADER na região Centro (onde se situa as Terras de Sicó).

A região Centro representativa do investimento generalizado na Cultura, é bastante diversa, pois reflecte o cruzamento de tendências várias. Uma primeira separação faz-se entre a parte raiana e a restante. Os projectos na metade leste distinguem-se claramente do Centro ocidental pela sua maior aposta na educação e na cooperação, tanto nacional como internacional - neste caso das incentivadas políticas transfronteiriças - e também pelo menor peso dos projectos que envolvem a comercialização, privilégio dos territórios que enquadram as montanhas e a sequência que se ligam ao Ribatejo. Os projectos em que a agricultura mais pontua fazem também sobressair toda a faixa de territórios transfronteiriços e os que envolvem o sistema Estrela - Cova da Beira prolongando-se, para norte, até a raia nordestina (MORENO, 2009, p.128).

Por meio das visitas de campo não foram observadas alterações significativas no perfil dos projetos cofinanciados pelo PRODER nas Terras de Sicó, comparando-se a IC LEADER (pois, de fato o atual programa se manteve fiel ao anterior em suas grandes linhas).

No território Terras de Sicó foram destinados $7.938 .467,72 €^{14}$ no âmbito do PRODER, entretanto, desse valor haviam sido executados 2.913.026,79€ (36,7\%) de acordo com as visitas de campo. No levantamento elaborado pela ADL- Terras de Sicó (referente à aprovação de 4,1 milhões de euros) tinha-se a seguinte configuração, apresentada na tabela 2 .

Tabela 2. Implementação parcial do PRODER nas Terras de Sicó.

\begin{tabular}{|l|c|c|c|c|}
\hline Ações & $\mathbf{N}^{\mathbf{o}}$ de Projetos & $\begin{array}{c}\text { Postos de } \\
\text { trabalho a } \\
\text { gerar }\end{array}$ & $\begin{array}{c}\text { Valor apoiado } \\
\text { (em mil euros) }\end{array}$ & $\begin{array}{c}\text { Invest. } \\
\text { Total } \\
\text { (em mil euros) }\end{array}$ \\
\hline $3.1 .2-\mathrm{CDM}$ & 26 & 52 & 1.900 & 3.300 \\
\hline $3.1 .3-\mathrm{DATL}$ & 8 & 15 & 920 & 1.700 \\
\hline $3.2 .1-\mathrm{CVPR}$ & 8 & 6 & 375 & 626 \\
\hline $3.2 .2-\mathrm{SBPR}$ & 14 & 40 & 949 & 1.200 \\
\hline Total & $\mathbf{5 6}$ & $\mathbf{1 1 3}$ & $\mathbf{4 . 1 0 0}$ & $\mathbf{6 . 8 0 0}$ \\
\hline
\end{tabular}

Fonte: $<$ http://www.terrasdesico.pt $>$. Org. Flávio de Arruda Saron.

13. Nos estudos de Moreno (2002 e 2009) é apresentado uma tipificação dos projetos do LEADER em Portugal continental.

14. Os valores destinados a cada GAL são decididos no âmbito da equipe gestora nacional do PRODER, vinculada ao Ministério da Agricultura e do Mar. O representante da ADL-Terras de Sicó não citou quais critérios são levados em consideração na definição do valor destinado a cada GAL, mas apontou que a não execução total do montante acarreta na sua diminuição num período seguinte. 
A observação da tabela 2 permite verificar o quão tímidos são os resultados do PRODER nas Terras de Sicó, especialmente se considerarmos o pequeno número de empregos gerados e o seu baixo impacto econômico, embora, não deixe de ser importante frente à pequena força interna do território em superar a sua condição marginal.

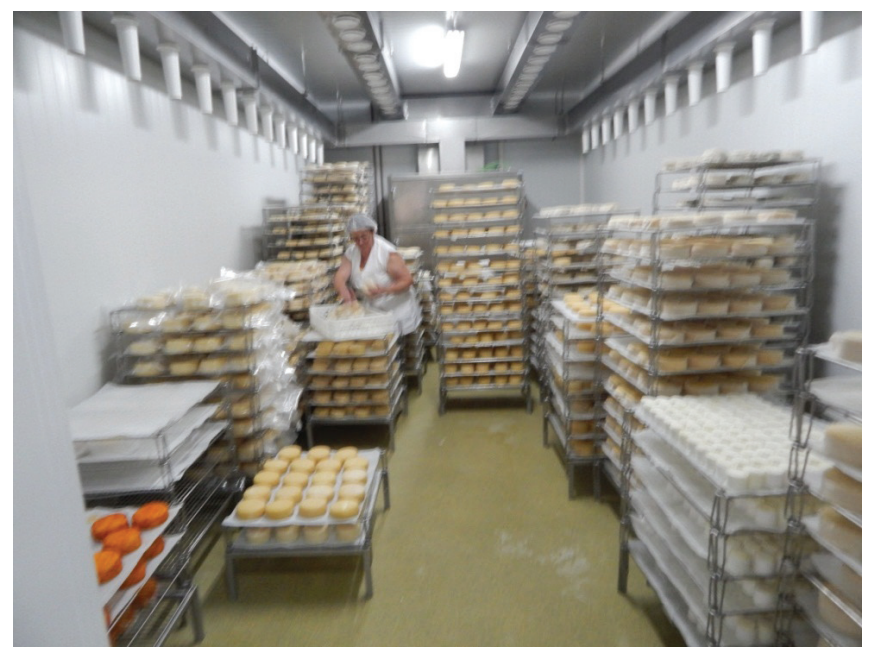

Figura 4. Queijos produzidos pela Queijaria Licínia.

A queijaria inaugurada há cerca de 20 anos com o apoio do LEADER I produz o queijo rabaçal, atualmente processa em média de 3 a 5 mil litros de leite de ovelha diários produzidos por 70 produtores das proximidades (que produzem de 5 1/dia a 1.300 1/dia), e emprega 16 funcionárias. Trata-se de um projeto que reforça um das marcas das Terras de Sicó, o queijo rabaçal.

Fonte: Pesquisa de Campo, 29/08/2013. Org. Flávio de Arruda Saron.

De maneira geral, pode-se observar que há projetos e ações, que embora possam ser importantes não têm muitos impactos no sentido de reverter à estagnação econômica do território, pois apenas a Medida 3.1 e Ação 3.1.2 - CDM e Ação 3.1.3 - DATL, e Medida 3.4 ação 3.4.2 Cooperação Transnacional têm efeitos mais significativos para o fomento ao dinamismo econômico. A figura 5 retrata um dos projetos cofinanciados pelo PRODER com baixo impacto econômico.

Na ação 3.4.2 - Cooperação Transnacional15, existe um projeto denominado Cooperar em Português que envolve várias ADLs portuguesas, dentre elas a ADL-Terras de Sicó, além de outros agentes como a Universidade de Coimbra, instituições de ensino técnico e profissional, câmaras municipais (inclusive dos municípios das Terras de Sicó). Dentre os vários objetivos estabelecidos para esse projeto está a prospecção de oportunidades de negócio a empresas sediadas nas Terras de Sicó.

15. Não foram encontrados, nem disponibilizados os valores alocados por meio desta ação. 
Com o apoio do PRODER são realizados eventos e fóruns para divulgar os produtos das Terras de Sicó nos países lusófonos (prioritariamente o Brasil), como o queijo rabaçal, o mel da Serra Lousã e o vinho Sicó, dentre outros produtos do território que poderão proporcionar algum resultado na dinamização econômica do território.

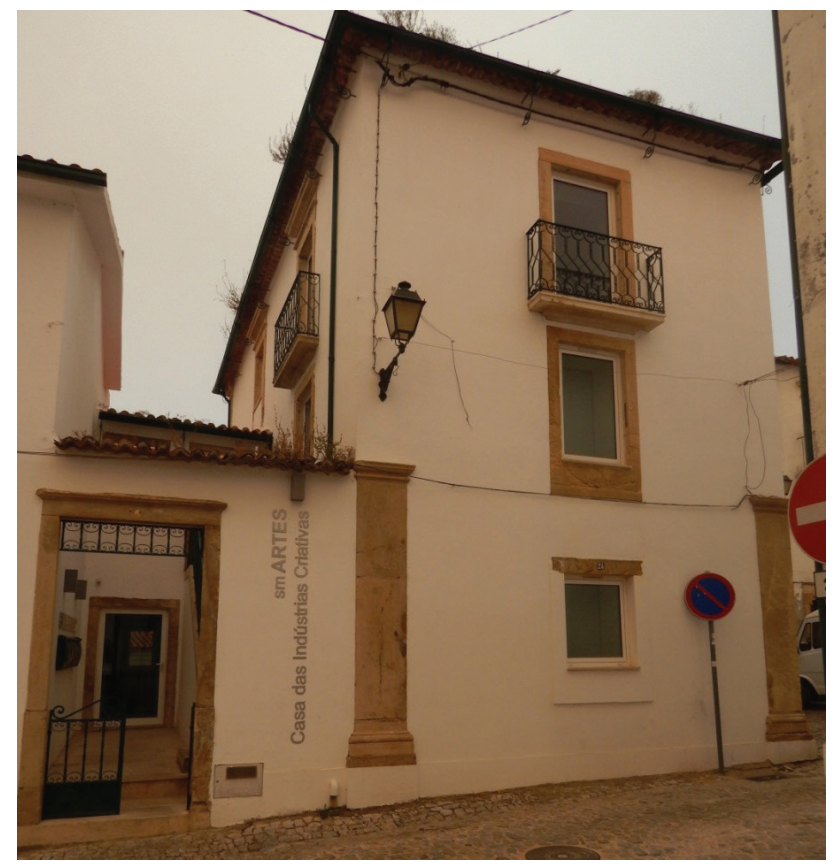

Figura 5. Projeto cofinanciado pelo PRODER no Concelho de Penela, Terras de Sicó.

Trata-se de um prédio construído para abrigar empresas de filmagem, as quais já se encontravam instaladas.

Fonte: Pesquisa de Campo, 29/08/2013. Org. Flávio de Arruda Saron

Operando apenas com o subprograma 3 do PRODER (eixo LEADER) a ADLTerras de Sicó tem atuação limitada no que tange ao impulso ao desenvolvimento. A organização constitui-se num instrumento de implementação de ações de apoio ao desenvolvimento rural, sob os desígnios das decisões políticas definidas em outras instâncias, como o Ministério da Agricultura e do Mar e a Comissão Europeia, nos âmbitos de Portugal e da União Europeia, respectivamente.

Este arranjo, explica o posicionamento e o perfil dos projetos apoiados pela ADL, que levam em consideração as características do território (agricultura frágil, existência de valores turísticos, proximidade de cidades médias etc.) e suas respectivas potencialidades e entraves para a implementação dos projetos de desenvolvimento local, descritos por Cunha (2003).

Como principais valores, recursos e potencialidades do Maciço de Sicó recordemos as características da paisagem, a riqueza do património histórico, 
o valor da biodiversidade, a importância estratégica da água que circula no seu interior e a fraca degradação ambiental que se regista e que é facilmente perceptível em qualquer rápida visita pela região. Constituem também importantes potencialidades a localização geográfica do Maciço, muito perto de Coimbra e Pombal, a boa qualidade das acessibilidades rodoviárias, uma identificação regional bem marcada e sentida e, ainda, a experiência de colaboração intermunicipal (materializada na criação e funcionamento da Adsicó/Terras de Sicó) com mais de uma dezena de anos.

Entre os principais entraves a políticas de desenvolvimento contam-se problemas de natureza demográfica (fraca densidade populacional, população envelhecida, fraco dinamismo demográfico), o baixo nível cultural e a fraca qualificação académica da população; a estrutura fundiária com forte fragmentação da propriedade rural; fraco desenvolvimento económico, a falta de equipamentos de diferentes tipos e, mesmo, alguma relação de conflitualidade entre actividades económicas de relevo (pedreiras, indústrias agroalimentares) e as necessárias salvaguardas ambientais (CUNHA, 2003, p.199).

Esse quadro interno ao território Terras de Sicó, aliado as restritas opções oferecidas pela IC LEADER e o subprograma 3 do PRODER se reflete na diversidade de natureza diferenciada das ações e projetos de desenvolvimento rural implementados pela ADL-Terras de Sicó.

A partir da breve pontuação dos projetos implementados nas Terras de Sicó com o incentivo da IC LEADER e do PRODER, percebe-se o esforço em produzir itens com maior valor agregado, e "vender" os atributos particulares do território, como o saber fazer, as condições naturais de produção (solo, flora que influenciam na característica do queijo, vinho, mel e outros produtos). Estas medidas consideradas alternativas, têm se convertido em convencionais, uma vez que muitos territórios rurais abrangidos pelo LEADER/PRODER em Portugal adotam este modelo, explicitando os limites da abordagem LEADER.

Constituem-se projetos de desenvolvimento rural de pequeno porte, que buscam alcançar pequenas fatias do mercado, de certa forma adequados a um território que não dispõe de competitividade na agricultura, em virtude das suas próprias condições naturais (relevo, solos pobres etc.), e também social e demográfica, como o envelhecimento da população e o baixo número de jovens. Tais projetos são importantes, porém insuficientes.

O representante da ADL-Terras de Sicó defende um modelo de financiamento multifundo (FEDER, FSE e FEADER) para o PRODER (subprograma 3, eixo LEADER), pois em sua avaliação o programa e as ações para o desenvolvimento rural requerem mudanças nas orientações, que além da sustentabilidade passem a considerar também a competitividade. Ou seja, para que os programas de desenvolvimento rural tenham como repertório mais do que ações paliativas para que consigam alterar a condição marginal dos territórios rurais deprimidos.

Nestes territórios, são necessárias ações consistentes para a reversão deste quadro, requerendo maior intervenção estatal, diferentemente do modelo em vigência nos programas de desenvolvimento rural. 


\section{Considerações finais}

De modo geral a IC LEADER e o PRODER pouco alteraram o quadro econômico e social dos territórios rurais deprimidos de Portugal, a exemplo das Terras de Sicó, onde os seus efeitos se limitaram a atenuar a estagnação econômica destes territórios.

O cenário de grande parte dos territórios rurais deprimidos de Portugal, da mesma forma que as Terras de Sicó, é fortemente marcado pelo envelhecimento da população rural e escassez crônica de jovens, e consequentemente, contingente reduzido de População Economicamente Ativa (PEA), o que dificulta a consecução dos objetivos dos programas de fomento ao desenvolvimento rural, pautados na abordagem territorial, como a IC LEADER e o PRODER. Pois, estes territórios não constituem ambientes propícios para o surgimento de iniciativas inovadoras conforme preconizam os programas.

Não é muito apropriado que as atribuições ao desenvolvimento recaiam sobre a população rural envelhecida, com baixos níveis de escolaridade e sem formação profissional. Nesse sentido, o arranjo atual dos programas de desenvolvimento rural (IC LEADER e PRODER), os instrumentos, a operacionalização, e, principalmente, as ações apoiadas e o orçamento estabelecidos precisam ser revistos. Os territórios rurais deprimidos portugueses, dentre eles, as Terras de Sicó necessitam de mais do que programas compensatórios, como a IC LEADER e o PRODER.

Cunha (2004), oportunamente lembrou que a agricultura e o espaço rural português necessitam de medidas do primeiro pilar da PAC, e estas revisões são atribuições das instâncias centrais de poder, como o Ministério da Agricultura e do Mar e a Comissão Europeia. Outra revisão necessária é a orientação neoliberal imposta aos países da porção mediterrânea da Europa (os mais afetados pela crise econômica de 2008), restringindo a capacidade de intervenção dos governos mediante quadros de recessão econômica.

As ADLs são controladas em grande medida pelas câmaras municipais e juntas de freguesias (autarquias públicas), que por seu turno, não expressam os interesses populares e por extensão da agricultura familiar (ROVER e HENRIQUES, 2006). Portanto, essas organizações, inclusive a ADL-Terras de Sicó têm uma existência marcadamente prática e formal, orientadas para o acesso aos programas de desenvolvimento rural, dos quais são amplamente dependentes, não dispondo de condições e instrumentos para conduzir os territórios rurais deprimidos ao desenvolvimento.

Portanto, os ínfimos resultados em relação à potencialização no desenvolvimento dos territórios rurais deprimidos, a insuficiência dos programas de desenvolvimento rural em conter tendências e processos de longa data, a exemplo do despovoamento das áreas rurais e a fragilização da agricultura, mantêm atual o debate sobre as estratégias de desenvolvimento para o(s) território(s) rurai(s) deprimidos. 


\section{Referências}

BARROS, Vitor Coelho. Intervenção Pública, 1996-2002. 1ª ed. Lisboa, Portugal: Terramar, 2003.

BAPTISTA, Fernando Oliveira. O rural depois da agricultura. In: Desenvolvimento e Território: espaços rurais pós-agrícolas e novos lugares de turismo e lazer. FONSECA, Maria Lucinda (Org.). $1^{\mathrm{a}}$ ed. Centro de Estudos Geográficos da Universidade de Lisboa, Lisboa, 2006, p. 85-105.

CARNEIRO, Inês Ferreira. O desenvolvimento rural em Portugal: caminhos percorridos e por percorrer...A contribuição do Programa de Iniciativa Comunitária LEADER para uma Política de Desenvolvimento Rural em Portugal. In: Actas da Conferência de Políticas Públicas para o Desenvolvimento, 2005 - Lisboa. Anais..., p. 1-22. Disponível em: <http://www.cetrad.info/static/docs/documentos/105.pdf>. Acesso em 19/06/2013.

CARVALHO, Paulo. União Europeia, políticas públicas e desenvolvimento rural. In: Cadernos de Geografia, Coimbra, no 26/27, 2007/2008, p. 67-76.

CAVACO, Carminda. Enquadramento macroeconómico: mudança e crise. In: MEDEIROS, Carlos. A. (Org.). Geografia de Portugal, Actividades Económicas e Espaço Geográfico (Vol. 3). $1^{\mathrm{a}}$ ed. Círculo de Leitores: Lisboa, 2006, p. 34-45.

. Portugal Rural: da tradição ao moderno. $1^{\mathrm{a}}$ ed. Lisboa, Portugal: Ministério da Agricultura, 1992.

COMISSÃO EUROPEIA. A politica agrícola comum - A história continua.

Luxemburgo: Serviço das Publicações da União Europeia, 2012.

COMUNIDADES EUROPEIAS. A abordagem LEADER, um guia básico. Comissão Europeia. Bruxelas, 2006.

CUNHA, Arlindo. A política agrícola comum na era da globalização. $1^{\mathrm{a}} \mathrm{ed}$. Coimbra: Almedina, 2004.

CUNHA, Lúcio. Maciço de Sicó. Valorização dos recursos naturais e criação de emprego a nível local. In: CAETANO, Lucília (Org.). Ter Territórios, do global ao local e trajectórias de desenvolvimento. $1^{\mathrm{a}}$ ed. Coimbra: CEGC, 2003, p. 185-202.

JACINTO, R., MENDES, T.; BAPTISTA, F. O. Os territórios de baixa densidade em tempos de mudança. 1. ed. Câmara Municipal de Proença-a-Nova e Centro de Vivência das Florestas, p. 121-132, 2009.

JACINTO, Rui; ALVES, Carolina. Refuncionalização dos espaços rurais de montanha: desindustrialização e turismo no Concelho de Manteigas. In: JACINTO, Rui (Org.). Paisagens, Patrimónios Turismo e Cultura. 1ª ed. Guarda: CEI, 2013, p.125-157.

LOPES, José M. Fidalgo. A (re)invenção do local: o papel das Associações de Desenvolvimento Local e o programa LEADER. 2012, 160f. Dissertação (Mestrado em Sociologia). Faculdade de Economia da Universidade de Coimbra.

MATEUS, Maria de L. P. da F. Roxo. Campos de Coimbra: do rural ao urbano. 2009. 423f. Tese (Doutorado em Geografia). Faculdade de Letras da Universidade de Coimbra. 
MORENO, Luis. Desenvolvimento local em áreas rurais: processo e expressão em Portugal Continental. In: CAVACO, Carminda (Org.). Repensar Portugal na Europa: perspectivas de um país periférico. $1^{\mathrm{a}}$ ed: CEG, EPRU, 2004, p. 103-137.

. Empreendedorismo e promoção territorial em áreas rurais. In: JACINTO, R., MENDES, T.; BAPTISTA, F. O. Os territórios de baixa densidade em tempos de mudança. 1. ed. Câmara Municipal de Proença-a-Nova e Centro de Vivência das Florestas, p. 121-132, 2009.

ROVER, Oscar J.; HENRIQUES, Maria A. A gestão democrática em debate: O programa LEADER e a sua relação com a sociedade civil local. In: Revista Crítica de Ciências Sociais, Coimbra-Portugal, $n^{0} 75$, p. 117-137, Outubro de 2006. Disponível em: < http://rccs.revues.org/905>Acesso em 20/06/2013.

SILVA, Manuel Carlos. A agricultura portuguesa, o Estado e a PAC europeia. In: Sociedade e Cultura 1, Cadernos do Noroeste, Braga-Portugal, vol. 13 (1), 2000, p.51-80. Disponível em: <http://cics.uminho.pt/pt/publicacoes-antigas/>. Acesso em 27/06/2013.

WERNER, Klaus. El movimento LEADER em Europa: balance y perspectivas. In: GUTIÉRREZ, Fermín Ramon (Org.). Manual de Desarrollo Local. $1^{\text {a }}$ ed. Espanha: Trea, 1999, p. 494-512.

Flávio de Arruda Saron

Licenciado e Bacharel em Geografia pela Universidade Estadual Paulista "Júlio de Mesquita Filho", Faculdade de Ciências e Tecnologia (FCT), Campus de Presidente Prudente.

Rua Roberto Simonsein, Departamento de Geografia, Sala 02 da Central dos Grupos de Pesquisa. Jardim das Rosas. Cep: 19060900 - Presidente Prudente, SP - Brasil.

flaviosaron@yahoo.com.br

Antonio Nivaldo Hespanhol

Graduado em Geografia pela UNESP - Campus de Presidente Prudente, mestre e doutor em Geografia pela UNESP - Campus de Rio Claro. Realizou estágio de pós-doutorado na Escola de Altos Estudos em Ciências Sociais (EHESS) em Paris-França. É Professor do Departamento de Geografia da UNESP - Campus de Presidente Prudente.

Rua Roberto Simonsen, 305, Cep: 19060-900 - P. Prudente, SP.

Email: nivaldo@fct.unesp.br

Recebido para publicação em novembro de 2014

Aprovado para publicação em março de 2015 